\title{
Determination of bioclimatic comfort in Sirjan desert
}

\author{
Tayebeh Mahmoodi $^{\mathbf{a}^{*}}$ and Mohammad Reza Iravani ${ }^{\mathrm{b}}$
}

${ }^{a}$ Department of Geography, University of Shahid Beheshti, Tehran, Iran

${ }^{b}$ Department of Social Work, Islamic Azad University of Khomeinishahr, Khomeinishahr Branch, Daneshjou Blvd, Iran

\begin{tabular}{l}
\hline A R T I C L E I N F O \\
\hline Article history: \\
Received July 25, 2011 \\
Received in Revised form \\
October, 12, 2011 \\
Accepted 18 December 2011 \\
Available online \\
3 January 2012 \\
\hline Keywords: \\
Climate \\
Bioclimate comfort \\
Sirjan \\
Kerman
\end{tabular}

\section{Introduction}

Weather condition plays an important role on people's life style and it is a primary motivation for many people's immigration purposes. Some people could match themselves with volatile weather but as they get older, it is getting more difficult to match with very hot or cold weather conditions. There are literally many studies to determine whether conditions and human comfort level (Lin et al., 2010; Hwang et al. 2010; Filippín et al., 2010).

Evans (2003) used a graphic design tool for evaluating comfort with varying temperatures and he presented the development of the graph using different examples with special emphasis on the use of thermal mass. Manioğlu and Y1lmaz (2006) investigated economic evaluation of the building envelope and operation period of heating system in terms of thermal comfort. They explained about the importance of providing thermal comfort conditions for users with a minimum heating energy cost and determined the primary parameters influencing heating energy consumption.

\footnotetext{
${ }^{*}$ Corresponding author. Tel: +989123509871

E-mail addresses: n.tab358@yahoo.com (N. Tabrizi)

(C) 2012 Growing Science Ltd. All rights reserved. doi: $10.5267 /$ j.msl.2012.01.001
} \begin{abstract}
bioclimatic comfort physiologically influences on human body's characteristics. In this paper, we present an empirical study on bioclimatic comfort in Sirjan desert located in the province of second during the daily hours only during the month of September, which causes comfort on people's body. However, even this velocity cannot cause comfort during the night. During the months of March, April and October, whether maintains a velocity of 0.1 meter/second, which brings comfort and it is possible to live with simple dress. During the months of May, June and July it is possible to reach comfort with simple cover during the night. It is possible to reach the
same condition with thicker coverage in nightly hours during the months of May and September. However, it is not possible to reach comfort with thick dress any nightly hours of year.
\end{abstract}


Toy et al. (2007) investigated the bioclimatic comfort in three different land uses in the city of Erzurum. They calculated the human bioclimatic conditions in rural, urban and urban forest areas in the conditions in that city, where an extreme continental climate type occurs. They gathered the necessary data over a 10 -month period and human bioclimatic circumstances in these three various land-use segments were assessed based on human bioclimatic indices. In the study, thermohygrometric index (THI), which measures air temperature and relative humidity, and "beer garden days" index, which implements the days when temperature at $21: 00$ is over $20{ }^{\circ} \mathrm{C}$, were incorporated. While in these three regions "hot" and "comfort" changes were determined to be $10 \%$ of the time, the number of "beer garden" days was only 20 days in rural, 15 days in urban forest and 18 days in urban areas of Erzurum. Therefore, the most suitable area for the human comfort in the conditions of Erzurum was nominated in the urban area, which is in the urban forest and the rural areas.

Zengin et al. (2010) performed a comprehensive investigation to determine bioclimatic comfort in Erzurum-Rize expressway corridor using GIS. They measured the climate data including temperature, relative humidity, wind speed from nine various stations. The results of this study explained that the area, which starts from south of the Mountains Mescit and it is started by Black Sea coastline to Mountain Mescit (3230 m) is out of bioclimatic comfort region. The Erzurum depression $(1758 \mathrm{~m})$, which starts from the Mountains Mescit has bioclimatic comfort conditions. They concluded that one of the ideal area, which has bioclimatic comfort is the Erzurum depression area in Turkey.

Gaitani et al. (2007) studied the use of bioclimatic architecture principles to improve thermal comfort conditions in outdoor environments. They investigated different techniques based on bioclimatic architecture criteria based on passive cooling and energy conservation principles to improve the thermal comfort conditions in an outdoor space location located in the Great Athens area. They calculated the thermal comfort conditions in 12 different outdoor space points using two various thermal comfort bioclimatic indices developed for outdoor spaces implications. They did their analysis during the summer time and two various scenarios of the constructed space parameters were considered. The first scenario contained a traditionally constructed space, while the second one incorporated different architectural improvements. They used these two bioclimatic indicators to calculate the outdoor thermal comfort conditions for both scenarios and they analyzed the influence of the bioclimatic design architectural improvements on the human thermal comfort sensation.

Mahmoud (2011) presented an analysis for bioclimatic zones and implications for design of outdoor built environments in Egypt and recommended a design guideline matrix for landscape architectural design for the different bioclimatic zones. Omer (2008) presented a comprehensive renewable building energy systems and passive human comfort solutions. He explained different designs of lowenergy buildings and outlined the impact of dense urban building nature on energy consumption, and its contribution to climate change. Dili et al. (2010) investigated thermal comfort behavior of Kerala traditional residential buildings based on questionnaire survey among occupants of traditional and modern buildings.

In this paper, we present a comprehensive study to measure comfort figures in one of the regions of Iran called Sirjan. The orientation of this paper first presents details of our methodology in section 2 and details of our finding are given in section 3. The paper ends with the concluding remarks in section 4 .

\section{Proposed study}

Sirjan is one of cities in province of Kerman, which is located from east between $54^{\prime} 57^{\prime \prime}$ and $5627^{\prime \prime}$ and from north between $28^{\prime} 42^{\prime \prime}$ to $30^{\prime} 01^{\prime \prime}$. The city has 13552.811 square kilometers and it is about 7.5 percent of the province of Kerman. The city is located in west part of the province and the cities of 
Rafsanjan and ShahreBabak are located in north of the city. The city is surrounded from the province of Hormozgan and from the East, it is surrounded from the province of Fars. Fig. 1 shows demographical position of the city.

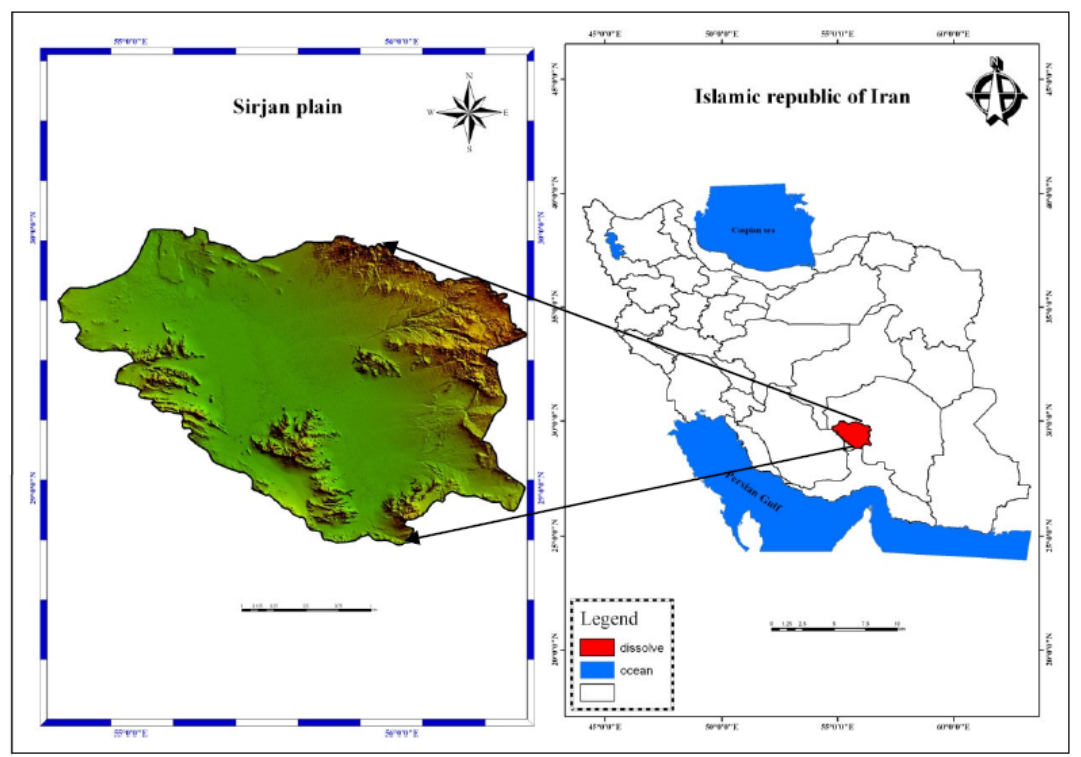

Fig. 1. Geographical location of city of Sirjan

In this study, we measure three different conditions of humidity, airflow and clothing to determine bioclimatic comfort. In the first step, topography maps in the scale of $1 / 50,000$ are prepared and then we analyze mean temperature as well as relative humidity based on Evans method (2003) and based on the min and the max of humidity and temperatures we measure comfort ratios for the city. Evans divides the relative humidity into four groups of 0\%-30\%, 30\%-50\%, 50\%-70\% and 100\%. Airflow according to Evans model is distributed from 0.1 meter/second called invisible to $1 \mathrm{~meter} / \mathrm{second}$ called visible. Dress code is distributed from thin summer type comfortable one to winter type. Finally, activity is also categorized from relaxing at home to hard work.

\section{Results}

Evans table is used for this investigation and Table 1 shows the details.

\section{Table 1}

Comfort regions based on weather condition, relative humidity, day and night temperature

\begin{tabular}{|c|c|c|c|c|}
\hline Scale & Weather condition & Relative humidity & Day temperature & Nigh temperature \\
\hline \multirow{4}{*}{ A } & \multirow{4}{*}{$\begin{array}{l}\text { Comfortable region when } \\
\text { airflow is one meter per second }\end{array}$} & $0-30$ & $29.5-32.5$ & $27.5-29.5$ \\
\hline & & $30-50$ & $28.5-30.5$ & $26.5-29.0$ \\
\hline & & $50-70$ & $27.5-29.5$ & $26-28.5$ \\
\hline & & $70-100$ & $26-29$ & $25.5-28$ \\
\hline \multirow{4}{*}{ B } & Comfortable region based on & $0-30$ & $22.5-30$ & $20-27.5$ \\
\hline & \multirow{3}{*}{$\begin{array}{l}\text { light dress during the day and a } \\
\text { simple cover during the night } \\
\text { with airflow of } 0.1 \\
\text { meter/second }\end{array}$} & $30-50$ & $22.5-28$ & $20-26$ \\
\hline & & $50-70$ & $22.5-27.5$ & $20-26$ \\
\hline & & $70-100$ & $22.5-27$ & $20-25.5$ \\
\hline \multirow{4}{*}{$\mathrm{C}$} & \multirow{4}{*}{$\begin{array}{l}\text { Comfortable region using } \\
\text { regular dress during the day } \\
\text { and thick cover during the } \\
\text { night }\end{array}$} & $0-30$ & $18-22.5$ & $16-20$ \\
\hline & & $30-50$ & $18-22.5$ & $16-20$ \\
\hline & & $50-70$ & $18-22.5$ & $16-20$ \\
\hline & & $70-100$ & $18-22.5$ & $16-20$ \\
\hline
\end{tabular}


Based on the Evans's model, we have measured the comfortable scales for both daily and nightly events of the city of Sirjan and the results are summarized in Table 2.

Table 2

Comfortable figures for the city of Sirjan

\begin{tabular}{llllllllllllll}
\hline Scale & Jan. & Feb. & March & April & May & June & July & Aug. & Sept. & Oct. & Nov. & Dec. & Comfortable \\
\hline A & Cold & Cold & Cold & Cold & Cold & Mild & Warm & Warm & Warm & Cold & Cold & Cold & \\
B & Cold & Cold & Cold & Mild & Mild & Warm & Warm & Warm & Warm & Mild & Cold & Cold & Day time \\
C & Cold & Cold & Cold & Warm & Warm & Warm & Warm & Warm & Warm & Warm & Cold & Cold & \\
\hline A & Cold & Cold & Cold & Cold & Cold & Cold & Cold & Cold & Cold & Cold & Cold & Cold & \\
B & Cold & Cold & Cold & Cold & Cold & Mild & Mild & Mild & Cold & Cold & Cold & Cold & Night time \\
C & Cold & Cold & Cold & Cold & Warm & Warm & Warm & Warm & Mild & Cold & Cold & Cold & \\
\hline Total & Cold & Cold & Cold & Mild & Mild & Warm & Warm & Warm & Mild & Mild & Cold & Cold & Day \\
& Cold & Cold & Cold & Mild & Mild & Mild & Mild & Mild & Mild & Mild & Cold & Cold & Night \\
\hline
\end{tabular}

According to the results of Table 2 we can conclude that velocity of air can reach one meter per second during the daily hours only during the month of September, which causes comfort on people's body. However, even this velocity cannot cause comfort during the night. During the months of March, April and October, whether maintains a velocity of 0.1 meter/second, which brings comfort and it is possible to live with simple dress.

During the months of May, June and July it is possible to reach comfort with simple cover during the night. It is possible to reach the same condition with thicker coverage in nightly hours during the months of May and September. However, it is not possible to reach comfort with thick dress any nightly hours of year. Table 3 shows the months of the year when we need to increase/decrease the temperature to increase the level of comfortable.

\section{Table 3}

Increase/decrease temperature needed for comfortable increase based on Evans model

\begin{tabular}{|c|c|c|c|c|c|c|c|c|c|c|c|c|c|c|}
\hline Time & Jan. & Feb. & March & April & May & June & July & August & Sept. & Oct. & Nov. & Dec. & Freq. & Freq. $\square$ \\
\hline Night & $\square$ & $\square$ & $\square$ & $\square$ & & & & & & $\square$ & $\square$ & $\square$ & 0 & 7 \\
\hline Day & $\square$ & 口 & 口 & & & घ & घ & a & & & ㅁ & ㅁ & 3 & 5 \\
\hline
\end{tabular}

- indicates the months where a reduction in temperature is requested for climate comfort

$\square$ indicates the months where an increase in temperature is requested for climate comfort

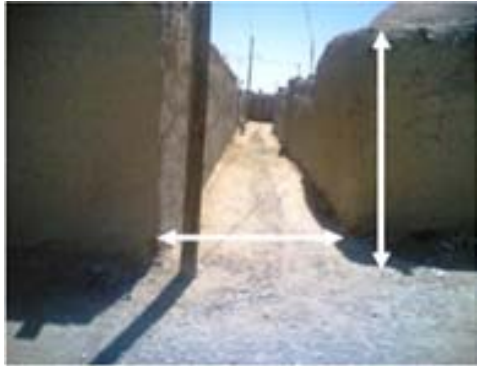

Fig. 1. Appropriate distances of walls and walking roads

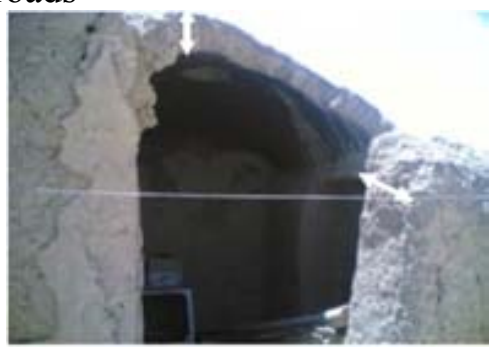

Fig. 3. The thickness of the roof

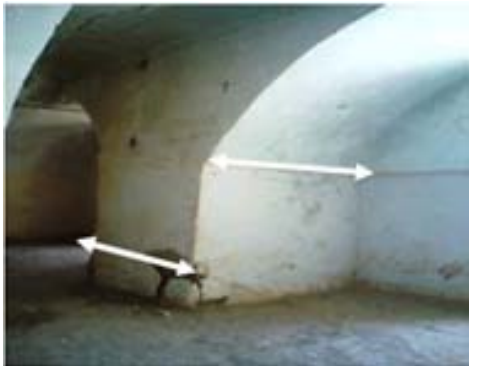

Fig. 2. Heavy walls

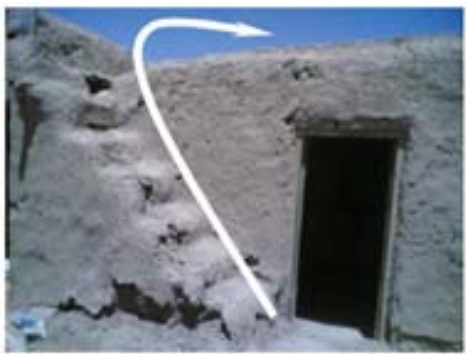

Fig. 4. Sleeping places during the night time 
Fig. 1 to Fig. 4 show some of the architectural perspectives of traditional buildings. As we can observe, people used to build their house to take advantage of airflow to reduce the temperature during the daytime. They also preferred to use sleep outside during the nighttime as we can see in Fig. 4. Note that it is not possible to maintain an appropriate building to keep comfort temperature all the time and we need to use other facilities to reduce/increase the temperature. Makaremi et al. (2012) investigated thermal comfort conditions of shaded outdoor spaces in hot and humid climate of Malaysia, which is similar to what we see in this region. In addition, we can observe that the most frequency of the night comfort belongs to summer time and the most frequency of the day comfort belongs to spring.

\section{Conclusion}

In this paper, we have presented an empirical study on bioclimatic comfort in Sirjan city located in the province of Kerman, Iran. The results of our study revealed that velocity of air could reach one meter per second during the daily hours only during the month of September, which causes comfort on people's body. However, even this velocity cannot cause comfort during the night. During the months of March, April and October, whether maintains a velocity of 0.1 meter/second, which brings comfort and it is possible to live with simple dress. During the months of May, June and July it is possible to reach comfort with simple cover during the night. It is possible to reach the same condition with thicker coverage in nightly hours during the months of May and September. However, it is not possible to reach comfort with thick dress any nightly hours of year.

\section{Acknowledgment}

The authors would like to thank the anonymous referees for their comments on earlier version of this work.

\section{References}

Dili, A.S., Naseer, M.A., Zacharia Varghese, T. (2010).Thermal comfort study of Kerala traditional residential buildings based on questionnaire survey among occupants of traditional and modern buildings. Energy and Buildings, 42(11), 2139-2150

Evans, J. M. (2003). Evaluating comfort with varying temperatures: a graphic design tool. Energy and Buildings, 35(1), 87-93.

Filippín, C., Flores Larsen, S., Canori, M. (2010). Energy consumption of bioclimatic buildings in Argentina during the period 2001-2008. Renewable and Sustainable Energy Reviews, 14(4), 12161228.

Gaitani, N., Mihalakakou, G., \& Santamouris, M. (2007). On the use of bioclimatic architecture principles in order to improve thermal comfort conditions in outdoor spaces. Building and Environment, 42(1), 317-324.

Hwang, R.L., Lin, T.P., Cheng, M.J., \& Lo, J.H. (2010). Adaptive comfort model for tree-shaded outdoors in Taiwan. Building and Environment, 45(8), 1873-1879.

Lin, T.P., Matzarakis, A., \& Hwang, R.L. (2010).Shading effect on long-term outdoor thermal comfort. Building and Environment, 45(1), 213-221.

Mahmoud, A.H.A. (2011). An analysis of bioclimatic zones and implications for design of outdoor built environments in Egypt. Building and Environment, 46(3), 605-620.

Manioğlu, G., \& Y1lmaz, Z. (2006). Economic evaluation of the building envelope and operation period of heating system in terms of thermal comfort. Energy and Buildings, 38(3), 266-272.

Makaremi, N., Salleh, E., Zaky Jaafar, M., \& GhaffarianHoseini, A. (2012). Thermal comfort conditions of shaded outdoor spaces in hot and humid climate of Malaysia. Building and Environment, 48, 7-14.

Omer, A.M. (2008). Renewable building energy systems and passive human comfort solutions. Renewable and Sustainable Energy Reviews, 12(2), 1562-1587. 
Toy, S., Yilmaz, S., \& Yilmaz, H. (2007). Determination of bioclimatic comfort in three different land uses in the city of Erzurum, Turkey. Building and Environment, 42(3), 1315-1318.

Zengin, M., Kopar, I., \& Karahan, F. (2010). Determination of bioclimatic comfort in Erzurum-Rize expressway corridor using GIS. Building and Environment, 45(1), 158-164. 